\title{
Será a psicanálise uma pseudociência? Reavaliando a doutrina utilizando uma lista de multicritérios
}

Is psychoanalysis a pseudoscience?

Reevaluating the doctrine using a multicriteria list

¿Es el psicoanálisis una pseudociencia? Reevaluando la doctrina usando una lista de criterios múltiples

Clarice de Medeiros Chaves Ferreira

https://orcid.org/0000-0002-0766-1827

\section{RESUMO:}

Introdução: A psicanálise já foi classificada como pseudociência no passado. Karl Popper foi um daqueles que traçou objeções à doutrina psicanalítica, usando do critério da falseabilidade. Entretanto, a falseabilidade não pode mais ser considerada suficiente para resolver o problema, já que implica em dificuldades consideráveis, e melhores alternativas para abordar a questão estão disponíveis. Objetivo: Este artigo tem por objetivo avaliar o status científico da psicanálise em relação ao problema da demarcação. Método: Para fazer isso, o critério de Sven Ove Hansson foi utilizado: este consiste em um conjunto de condições suficientes e necessárias, que é complementado com uma lista de multicritérios que auxiliam a identificar pseudociências. Foi analisado o quanto a psicanálise se encaixava em cada um dos sete itens da lista de Hansson, além de ser proposta a adição de um oitavo item. Resultados: Os resultados mostraram que a psicanálise era compatível com todos os oito itens da lista de demarcação de pseudociências. Conclusão: Ao final, a conclusão foi de que mesmo que a falseabilidade deva ser descartada, as evidências sugerem que ainda temos motivos suficientes para afirmar que a psicanálise é uma pseudociência, já que ela se distancia significativamente dos padrões de qualidade científicos.

Palavras-chave: Psicanálise, Psicologia, Ciência 


\section{ABSTRACT:}

Introduction: In the past, psychoanalysis was classified as a pseudoscience. Karl Popper was one of those who objected to the idea that psychoanalysis is a science, using falsifiability. However, falsifiability cannot be considered sufficient anymore, since it carries major weaknesses and better alternatives to address the issue are available. Objective: This article intends to evaluate the scientific status of psychoanalysis concerning the demarcation problem. Method: In order to do so, Sven Ove Hansson's criteria was used: It consists of a set of sufficient and necessary conditions which is complemented by a multicriteria list that helps identifying pseudosciences. It was analyzed how much psychoanalysis fits each of Hansson's seven items, besides proposing the addition of an eighth. Results: The results showed that psychoanalysis was compatible with all eight demarcation of pseudoscience's items. Conclusion: In the end, the conclusion was that even if falsifiability was to be dismissed, the evidence suggests that there are still enough reasons to affirm that psychoanalysis is a pseudoscience, since it significantly deviates from scientific quality standards.

Keywords: Psychoanalysis, Psychology, Science

\section{RESUMEN:}

Introducción: En el pasado, el psicoanálisis fue clasificado como una pseudociencia. Karl Popper fue uno de los que objetó la doctrina psicoanalítica usando el criterio de la falsabilidad. Sin embargo, ya no se puede considerar la falsabilidad como suficiente para resolver el problema, ya que implicaría dificultades considerables y existen mejores alternativas para abordar este asunto. Objetivo: Este artículo pretende evaluar el estatus científico del psicoanálisis con respecto al problema de demarcación. Método: Para ello fue utilizada la propuesta de Sven Ove Hansson: ésta consiste en un conjunto de condiciones suficientes y necesarias, complementado con una lista multicriterios que ayuda a identificar pseudociencias. Se analizó que tanto el psicoanálisis se encaja 
en cada uno de los siete ítems de la lista de Hansson y además, se propone la adición de un octavo. Resultados: Los resultados mostraron que el psicoanálisis es compatible con todos los criterios de demarcación de pseudociencia. Conclusión: Al final, se concluyó que aún teniendo que descartar la falsabilidad, las evidencias sugieren que hay motivos suficientes para afirmar que el psicoanálisis es una pseudociencia, ya que ésta se desvía significativamente de los estándares de calidad científica.

Palabras clave: Psicoanálisis, Psicología, Ciencia

Como citar: Ferreira CMC - Será a psicanálise uma pseudociência? Reavaliando a doutrina utilizando uma lista de multicritérios. Debates em Psiquiatria, Rio de Janeiro, 2021; 11:1-33.

https://doi.org/10.25118/2763-9037.2021.v11.58

Conflito de interesses: declara não haver

Fonte de financiamento: declara não haver

Parecer CEP: não se aplica

Recebido em: 08/02/2021

Aprovado em: 30/04/2021

Publicado em: 13/09/2021 


\section{Introdução}

Laplanche e Pontalis [1] discorrem sobre a definição de psicanálise da seguinte maneira: fundada por Sigmund Freud, a psicanálise é um tratamento psicoterápico e um método de investigação (sobre o qual a psicoterapia se alicerça) que tem como objeto os significados inconscientes das produções humanas (palavras, ações, pensamentos, sonhos e outros). Além disto, a psicanálise também é um conjunto de teorias psicológicas e psicopatológicas, e as experiências provenientes da psicoterapia e do método investigativo forneceram sua base de sustentação.

Um dos autores mais famosos que chegou a objetar a doutrina, mais especificamente por questionar seu caráter científico, foi o filósofo da ciência Karl Popper. Sobre a psicanálise, Popper [2] argumenta que independentemente de qualquer ocorrência que dissesse respeito ao comportamento humano, os adeptos da psicanálise Freudiana poderiam interpretá-la à luz de sua própria teoria. Apesar de que intuitivamente uma teoria compatível com todo tipo de previsão e cenário possa soar atraente, para o autor isso não seria uma qualidade, mas sim uma debilidade teórica. Em sua visão, uma teoria que sempre se aplica ao mundo independentemente de como ele seja não diz algo de relevante sobre a realidade, pois assim, mesmo que tudo fosse completamente diferente de como é agora, ela continuaria soando como verdadeira.

Para julgar uma teoria que se comporta dessa maneira, Popper [2] utiliza a falseabilidade, que age como um critério de demarcação entre o que seria científico e o que não seria. A falseabilidade determina que, para que uma teoria seja científica, é necessário que exista a possibilidade de que ela esteja errada, e que possa ser eventualmente refutada diante de novos dados. Não basta que uma teoria seja capaz de explicar o mundo; é necessário ser concebível conferir se essas explicações são boas, e isso só seria alcançável se houvesse a possibilidade de que em algum cenário ela estivesse incorreta. Para o autor, a psicanálise tal como foi formulada seria aplicável em todas as circunstâncias e não haveria possibilidade de conferir se suas afirmações são de fato adequadas [2, p. 64-65]. Assim, o critério da falseabilidade é proposto para demarcar a ciência, com a psicanálise não se enquadrando na categoria.

Os comentários de Popper não passaram despercebidos, e ele também foi

4 Debates em Psiquiatria, Rio de Janeiro, 2021; 11:1-33

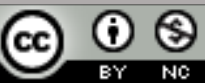

https://doi.org/10.25118/2763-9037.2021.v11.58 
criticado pela maneira como caracterizou a psicanálise. Sobre este debate, Grünbaum []ㅡ utilizou o exemplo da paranoia para defender que a teoria seria falseável. Grünbaum argumenta que, para a teoria Freudiana, todo indivíduo paranoico teria recalcado desejos de se relacionar sexualmente com indivíduos de seu próprio sexo; portanto, se hipoteticamente fosse encontrado um paranoico que não recalcava tais desejos, a teoria seria falseada, ou seja, haveria uma situação que ela não teria como explicar. Sobre isso, Cioffi [4] contra-argumenta que, mesmo se fosse o caso, esse tópico é periférico para a teoria psicanalítica, e utilizando-o como o contraexemplo final, outros candidatos mais importantes para enfrentar o critério Popperiano seriam desconsiderados, apontando então como exemplo a etiologia sexual das neuroses. O caso da paranoia é insuficiente para derrubar a crítica de Popper, por não ser parte dos pressupostos principais da doutrina.

Para além do criticismo sobre a psicanálise, a visão mais geral de ciência Popperiana que embasa a falseabilidade também sofreu objeções. Não há a pretensão aqui de se fazer uma exaustão destes contrapontos, mas podemos considerar alguns exemplos dados por Newton-Smith [ $\underline{5}$, p. 4476]: Popper rejeitaria que na ciência devamos utilizar raciocínios indutivos (previsões ou generalizações não dedutivas em que sua validade ou invalidade não dependem de sua forma lógica), tendo defendido que ela deveria operar apenas com raciocínios dedutivos (aqueles em que sua validade ou invalidade dependem exclusivamente de sua forma lógica), e desse modo, seria impossível confirmar qualquer teoria. É apenas possível saber que, caso ela seja falseada, é falsa. Porém, mesmo se uma teoria for falseada, se não existe outra melhor para explicar determinados fenômenos que possa substituí-la, e considerando também que essa primeira possui asserções minimamente razoáveis, talvez não seja prudente descartá-la apenas porque foi falseada. Além disso, sua concepção de ciência acaba inadvertidamente se justificando através de argumentos que na realidade dependem da indução, o que demonstra uma falha em sua proposta. Essas, mas também outras dificuldades inerentes à adoção da falseabilidade como critério de demarcação acabam por tornála insuficiente, o que leva à necessidade de uma proposta diferente.

\section{Método}

Sven Ove Hansson é um filósofo que teve um importante impacto no 
debate sobre o problema da demarcação, criando uma proposta alternativa: além de um critério com duas condições conjuntamente suficientes e necessárias para uma doutrina ser pseudocientífica [6] , também uma lista baseada em multicritérios que auxilia a identificar pseudociências, contendo sete itens [7]]. Esta tem a vantagem de não precisar enfrentar os mesmos problemas que os critérios anteriores, similares ao de Popper, enfrentaram. Antes de discuti-la, é proveitoso compreender primeiramente sua maneira de definir ciência:

"Ciência (no sentido ampliado) é a prática que nos fornece as afirmações mais confiáveis (i.e., epistemicamente justificadas) que podem ser feitas, em um determinado momento, sobre um objeto de estudos abarcado por uma comunidade de disciplinas de conhecimento (i.e., sobre a natureza, nós mesmos como seres humanos, nossas sociedades, nossas construções físicas, e nossas construções mentais)". [그, p. 70]

É recorrente a consideração de que a ciência diz respeito apenas às ciências da natureza, excluindo assim a linguística, matemática, filosofia, história e as humanidades da categoria. Entretanto, como aponta Hansson []], essa não é uma perspectiva adequada, pois tanto as ciências no sentido tradicional do termo quanto também as humanidades buscam fornecer as afirmações mais confiáveis sobre seus respectivos objetos de estudos. Neste sentido, é possível entender que elas seriam as teorias que apresentam as provas mais robustas sobre o que se propõem a investigar. Juntas, as ciências formam uma comunidade, e as disciplinas que a integram dependem umas das outras e cooperam entre si para atingirem esse objetivo.

É comum que se argumente que a psicanálise certamente é uma ciência, já que está presente no meio acadêmico, na pesquisa e nos departamentos de diversos cursos de ensino superior; ela estaria, portanto, fazendo parte da comunidade científica. Entretanto, "não é o status acadêmico, mas a metodologia e o tipo de conhecimento que devem determinar se a disciplina é científica (no sentido ampliado)" [ㄱ, p. 64]. Mesmo que ela seja reconhecida na academia, isso não a torna automaticamente uma ciência. Ainda que os homeopatas ou os criacionistas, por exemplo, começassem a criar cursos acadêmicos, publicassem artigos sobre suas teorias e realizassem congressos formais para reunir sua comunidade, não seria isso que tornaria a homeopatia ou o criacionismo ciências; o mesmo vale para outras doutrinas. 
Hansson [7] também aponta que mesmo dentro dos estudos das ciências humanas é necessário lidar com teorias extremamente dubitáveis, como os negacionistas do holocausto e teóricos dos antigos astronautas, por exemplo. Para evitar uma divisão entre pseudohumanidades e pseudociências, bem como para captar de maneira acurada a empreitada que busca fornecer as afirmações mais confiáveis que são possíveis de serem feitas em nossa época, a definição de ciência em seu sentido amplo é propícia.

Quando uma afirmação está apoiada em uma quantidade suficiente de provas, ela está epistemicamente justificada. Provas suficientes são aquelas que tornam uma crença segura, pois fornecem boas razões para se pensar que a hipótese proposta é provavelmente verdadeira. A ciência ser a prática que fornece as afirmações mais confiáveis significa que ela é a que apresenta as melhores e mais robustas provas sobre seus objetos de estudos. Controles e ajustes são constantemente feitos para se aproximar cada vez mais de uma descrição adequada da realidade.

Por exemplo, quando alguém deseja realizar uma investigação empírica sobre se um novo tratamento funciona ou não, um estudo randomizado, com controle de placebo e duplo-cego é mais confiável do que um relato de caso anedótico, por ter maiores chances de mostrar resultados que de fato refletem a realidade do que a anedota. Com o primeiro há uma sistematização de suas investigações e controle de vieses, o que é ausente no segundo. Nesse caso, para hipóteses que necessitam de análises empíricas do tipo, é mais adequado que se utilize do primeiro tipo de estudo justamente por ser aquele que fornece as melhores provas, e sua utilização adequada torna aquela investigação científica. Por outro lado, utilizar métodos com baixos padrões de qualidade de investigação, como os casos anedóticos, não seria científico.

Assim sendo, para Hansson [7] , pseudociências também podem ser versões fracassadas da ciência dentro das humanidades, e não apenas dentro das ciências em sua definição tradicional. Ele define uma pseudociência da seguinte maneira:

"Uma doutrina é pseudocientífica se e somente se satisfaz as seguintes duas condições:

A. Ela inclui ao menos uma afirmação que (A1) pertence a um assunto dentro dos domínios da ciência no sentido ampliado (o critério do domínio científico) e (A2) sofre de uma falta de confiabilidade tão severa ao ponto de não merecer ser confiada (o critério da não confiabilidade);

B. Seus principais proponentes tentam criar a impressão de que ela representa 
o conhecimento mais confiável em sua respectiva área (o critério da pretensão)" [ㅌ, p. 49-50].

Hansson tenta diferenciar disciplinas de doutrinas. Nem toda doutrina é pseudocientífica, mas toda pseudociência seria uma doutrina. Ele define uma doutrina a partir do dicionário de inglês de Oxford, sendo "um conjunto de afirmações que é 'ensinado ou colocado como sendo verdadeiro em relação a um assunto em particular ou um departamento de conhecimento'" [ㅌ, p. 49]. Em uma doutrina, metodologias e afirmações são pré-assumidas, e sem elas, não há mais doutrina. Em alguns casos, essas afirmações podem estar bem embasadas em evidências, como é para a teoria da evolução das espécies. Já em outros não, como o caso da psicanálise, o que será evidenciado nas próximas seções.

Similarmente ao que argumenta Hansson [ㅌ], caso as ideias mais centrais da doutrina psicanalítica fossem dela removidas, como por exemplo, sobre a existência de um inconsciente psicodinâmico, não existiria mais psicanálise. O mesmo acontece para a teoria da evolução das espécies: se dela fossem removidas as ideias de que os seres vivos passam por seleção natural, de que indivíduos mais adaptados têm maiores chances de sobreviver, ou outras afirmações, então nada sobraria. Isso é diferente de uma disciplina: em disciplinas, não existem metodologias ou afirmações pré-assumidas. Disciplinas se referem a um campo de estudos. Dois exemplos poderiam ser a psicologia (no caso em que não se assume uma abordagem psicológica de antemão), e a biologia, sendo vistas como "o estudo do comportamento" e "o estudo da vida", respectivamente.

Também é importante notar que não é preciso que os psicanalistas clamem que a psicanálise seja uma ciência; certamente, parte da comunidade concorda e outra discorda dessa afirmação, mas o que é explicitamente dito sobre a cientificidade não tem relevância. Se uma doutrina se comporta como se fosse uma ciência - ou seja, se a postura de seus proponentes implica que as afirmações da doutrina sobre o mundo são as mais confiáveis sobre seu objeto de estudos - independente de dizer explicitamente ser uma ciência ou não, ela já está qualificada para ser julgada pelos critérios de demarcação.

Mesmo após esses esclarecimentos, definir o significado de ciência e de pseudociência não elucida o que devemos investigar em uma doutrina específica para conferirmos se ela é pseudocientífica. Hansson []] aborda 
que demarcações propostas anteriormente não conseguiram, de fato, resolver a questão, sofrendo de severos criticismos. Ele propõe então uma alternativa: uma lista de multicritérios. Ela é construída em formato de uma lista de ações cometidas por um corpo de teorias pseudocientíficas, mas que, diferentemente de demarcações que utilizam critérios suficientes e necessários, não é exaustiva. Isso significa que uma teoria ou uma afirmação podem ser pseudocientíficas mesmo que não cumpram todos os critérios, e ainda que cumpram algum, existe a possibilidade de que não o sejam. Ela funcionaria como uma ferramenta para possibilitar avaliações mais práticas de doutrinas, para além de sua definição em critérios suficientes e necessários. É importante notar que na maioria dos casos se pelo menos um dos itens da lista estiver de acordo com a teoria avaliada, provavelmente ela é pseudocientífica. A proposta é a seguinte:

"1. Credo na autoridade: é afirmado que alguma pessoa ou pessoas têm uma habilidade especial de determinar o que é verdadeiro ou falso. Os outros precisam aceitar seus julgamentos.

2. Experimentos não repetíveis: a confiança é depositada em experimentos que não podem ser repetidos por outros com o mesmo resultado.

3. Exemplos escolhidos a dedo: exemplos escolhidos a dedo são usados apesar de não serem representativos da categoria geral à qual a investigação se refere.

4. Resistência à testagem: uma teoria não é testada apesar de ser possível fazêlo.

5. Desdém com informações refutantes: observações ou experimentos que conflitam com a teoria são rejeitados.

6. Construída em subterfúgio: a testagem de uma teoria é arranjada de tal maneira que ela pode apenas ser confirmada, e nunca desconfirmada, pelos seus resultados.

7. Explicações são abandonadas sem substituição: explicações sustentáveis são abandonadas sem serem substituídas, de forma que a nova teoria deixa muito mais coisas inexplicadas do que a anterior" [그, p. 72-73; $\underline{8}]$.

Ao final do sétimo item, por ser insuficiente em captar outros problemas relativos à maneira como se comportam certas explicações teóricas, haverá nesse trabalho a proposta de acréscimo de um oitavo: 0 obscurantismo. A partir dessa nova proposta de demarcação de pseudociências, amparada pela lista de multicritérios, será possível avaliar se a psicanálise é de fato pseudocientífica ou não, dependendo de como se relaciona com cada um dos itens descritos. 


\section{Resultados e Discussões}

\section{Credo na Autoridade}

A psicanálise é uma ciência "testemunhal" [4]; a base para seus conceitos teóricos está na interpretação dos casos clínicos de seus fundadores. Mesmo assim, o uso do argumento de autoridade não colhe se não houverem boas provas sobre o que dizem os autores. Freud não se fez valer de experimentos científicos sistematicamente controlados, nem mesmo do uso de estatística para chegar a suas conclusões [9], sendo necessário que o leitor que consulta as fundações da teoria confie que ele possuía capacidades que eram ao mesmo tempo diferenciadas e especiais para descobrir a verdade sobre o funcionamento psicológico humano. Entretanto, não há motivos para pensar que alguém que se utiliza apenas de sua experiência pessoal e decide não recorrer às ferramentas científicas teria condições de formular a teoria psicológica mais epistemicamente justificada.

Os outros autores da psicanálise também seguiram os passos de Freud. Para que se acredite nas colocações de Lacan, por exemplo, é necessário primeiro acatá-las como verdadeiras e atribuir a ele um papel de autoridade, já que o leitor não tem como comprová-las independentemente, nem tem recursos para compreender explicitamente seus significados [10]. Porém, para além disso, no caso do fundador, é possível que não existam motivos nem mesmo para acreditar na veracidade de suas narrativas. Na psicanálise, a honestidade de seus proponentes é um ponto importante de ser abordado, exatamente porque a teoria se baseia primariamente na autoridade deles [4]. Se não há honestidade, não deveria haver motivos nem para aqueles que desconhecem os problemas relativos às evidências anedóticas para continuarem a adotar seus pressupostos.

Dersken [11] nos aponta que Freud frequentemente usava de diversas estratégias retóricas para se esquivar das críticas e manter as boas aparências da psicanálise diante do público, tendo sucesso com isso. $O$ psicanalista já afirmou por diversas vezes que sua teoria não era especulativa, em uma tentativa de convencer o leitor de que havia uma suposta sólida base empírica por trás de suas conclusões, mesmo não

10 Debates em Psiquiatria, Rio de Janeiro, 2021; 11:1-33

(c) $(1)(9)$

https://doi.org/10.25118/2763-9037.2021.v11.58 
havendo. Para lidar com os contra-argumentos mais severos, ele tentava inverter os papéis: ele próprio apresentava as objeções do modo mais ameaçador possível para sua própria doutrina, dando a sensação para o leitor de que estava ciente do problema e, portanto, saberia respondê-lo. Afinal, qual outro motivo haveria para levantar tais críticas se não soubesse se defender delas? Mesmo assim, ao final do discurso, a suposta réplica era apenas evasiva, o assunto original era alterado, havia uma inversão do ônus da prova ou então absolutamente nenhuma resposta era dada, mantendo a crítica original em aberto.

Crews [9] nos mostra que Freud em muitas ocasiões ajustava suas narrativas para que se encaixassem no resultado que ele previamente já pretendia alcançar, independentemente de suas colocações serem fiéis à realidade. Diversos de seus casos clínicos ocorreram de modo distinto do que foi anunciado por ele, passaram por um processo interpretativo enviesado, ou não obtiveram resultados promissores: Anna O., na realidade, não era uma pessoa com histeria, mas sim sofria de uma dependência química de substâncias como morfina e hidrato de cloral, e todos os seus sintomas eram listados como possíveis efeitos do uso dessas [9 , p. 354-360]. Dora, jovem que foi vítima de assédio sexual, foi anunciada como protagonista de um caso de histeria por não desejar envolver-se com seu abusador e sentir repulsa em suas investidas [ $\underline{9}, \mathrm{p}$. 590-600]. Sobre o Pequeno Hans, de 5 anos, Freud não hesitou em darIhe um diagnóstico antes mesmo de conhecê-lo pessoalmente: seu medo de cavalos era na verdade um medo de ser castrado por seu pai, já que desejava sexualmente sua mãe [9, p. 645]. O Homem dos Lobos foi anunciado por ele como curado, entretanto, por décadas continuou passando por vários psicanalistas diferentes, não obtendo resultado algum $[\underline{9}$, p. $651 ; \underline{12}]$.

Esses são apenas alguns exemplos de certos casos clínicos populares, mas outros também sofrem do mesmo problema [9]]. O sucesso dessas adulterações e de outras estratégias retóricas contribuiu para a construção e reconhecimento de seu papel de autoridade, bem como o obscurecimento da fragilidade de sua proposta.

\section{Experimentos Não Repetíveis}

Como foi comentado anteriormente, a sustentação para os conceitos 
teóricos na psicanálise vem dos relatos dos casos clínicos de Freud e também dos outros principais proponentes do movimento, que seguiram a tradição de produção de evidências anedóticas. Até hoje, eles mantêm sua autoridade diante dos psicanalistas contemporâneos:
"André Green, perguntado sobre o que havia de novo em psicanálise, respondeu:
Freud. A esta resposta jocosa e, não obstante, muito verdadeira, poderíamos acrescentar a lista dos grandes pensadores e praticantes da psicanálise que marcaram as diversas tradições em que o movimento psicanalítico se repartiu desde a década de 40. Décadas depois de mortos, continuam a ser o que de novo existe, desde que os saibamos ler" $[13$, p. 10].

Apesar de evidências anedóticas ainda serem utilizadas, em grande maioria, como o principal meio de divulgação e produção psicanalítica [14], obstáculos significativos se impõem com o seu uso. Um caso clínico psicanalítico é um tipo de processo que não pode ser repetido, exatamente por se tratar de apenas um sujeito de modo individualizado. Entretanto, como argumenta Schmidt [15], a replicação é um dos processos mais centrais dentro das ciências empíricas, e infelizmente nem a própria psicologia dá a devida importância à questão. Ela possui cinco funções principais: controlar os erros amostrais, verificando se os resultados obtidos anteriormente foram por mera chance ou não; controlar a validade interna, ou seja, se os procedimentos adotados foram adequados para responder à pergunta da pesquisa; controlar a possibilidade de fraude científica; permitir uma generalização dos achados para uma população maior ou diferente; e por último, verificar se a hipótese do primeiro experimento de fato estava correta. No caso de uma experiência não repetível, há uma impossibilidade de realizar tais análises.

Para além da inviabilidade de replicação, também existem mais problemas, agora ligados ao próprio funcionamento psicológico humano: pessoas costumam ser vítimas de vieses cognitivos que distorcem seus julgamentos e as levam a interpretações irracionais com mais frequência do que costumam perceber [16], e os terapeutas não estão isentos disso. Um exemplo é o viés de confirmação: as crenças iniciais de alguém impactam de maneira significativa a forma como o sujeito se lembra dos acontecimentos e também como os interpreta, valorizando aquilo que aparentemente corrobora com sua visão de mundo e não dando atenção às possíveis informações que o contradizem. No caso de um psicanalista, isso pode levá-lo a entender exatamente aquilo que já esperava ouvir e que supostamente confirmaria a hipótese analítica, independente de aquilo 
de fato ser o caso [14, p. 139-140]. Mesmo que casos clínicos não sejam boas evidências, eles soariam como uma fonte de confirmação teórica para os adeptos. É esperado que reflitam suas preconcepções.

Como mostra Spence [17], mesmo se alguém analisar a veracidade dos próprios acontecimentos clínicos, ainda precisaria lidar com a questão de que estes costumam ser substituídos por uma narrativa ficcional. Os seus conteúdos podem ser apenas parcialmente reportados, omitidos, distorcidos e misturados com os conteúdos de casos diferentes, mesmo que de modo não intencional, exatamente por estarem baseados na memória do terapeuta. Como não são suficientemente controlados, quando casos clínicos psicanalíticos têm por objetivo dar suporte à uma teoria psicológica humana e são usados como método de investigação, acabam servindo apenas como combustível para um sistema de retroalimentação de confirmações. Não há como generalizar uma teoria psicológica humana a partir de evidências clínicas anedóticas e nem garantir confiabilidade, porque um processo não sistematizado não busca controlar variáveis que têm capacidade de interferir nas conclusões obtidas, enquanto também temos razões para esperar que as distorções aconteçam.

\section{Exemplos Escolhidos a Dedo}

O próprio uso majoritário de evidências anedóticas, como já foi discutido em seções anteriores, seria um bom exemplo também para o preenchimento deste terceiro critério, exatamente por se referirem a casos isolados e expostos a vieses. Porém, para além deles, outra empreitada da psicanálise contemporânea que se enquadra na situação é a neuropsicanálise. A neuropsicanálise é um movimento que busca uma comunhão entre neurociências e psicanálise, e apesar de ser rejeitada por uma parcela da comunidade psicanalítica que prefere distância da primeira, alguns a consideram uma das versões contemporâneas da teoria.

Callegaro [18, p. 207-220] aponta que, ao contrário do que o movimento neuropsicanalítico busca anunciar, na literatura há algo contrário à união: as evidências que existem no campo das neurociências costumam refutar ou entrar em choque direto com a psicanálise. Não é como se fosse plausível usar a psicanálise como um modelo de referência; é no modelo do novo inconsciente cognitivo que os neurocientistas estão se apoiando, e não no modelo psicodinâmico. 
Paris [14, p. 94-99] argumenta que a neuropsicanálise não está operando de modo a buscar avaliar as teorias Freudianas e neurocientíficas recentes imparcialmente, mas sim parte do princípio de buscar validar de antemão o modelo de Freud, que mostrou não ter hipóteses consistentes com a neurociência moderna. O autor lista então alguns motivos que mostram o porquê a neuropsicanálise está distante da ciência: nessa doutrina, já se começa assumindo que Freud estava correto, e a pesquisa serviria apenas para apontar o que já era óbvio na concepção psicanalítica; a maioria dos artigos de neuropsicanálise não apresentam dados concretos, mas especulações teóricas; os métodos usados para medir os conceitos básicos da psicanálise ainda são demasiadamente rudimentares; e, por fim, existem diversas dificuldades e problemas, até mesmo dentro da própria neurociência, para localizar adequadamente as funções mentais em regiões cerebrais específicas.

Ao final, podemos constatar que o trabalho da neuropsicanálise consiste em um cherry picking de dados, em que se "tenta sistematicamente associar quase todo conceito ou descoberta neurocientífica com uma citação de Freud" [19, p. 170], passando a impressão de que, quando se pareiam fenômenos neurológicos como a anosognosia, problemas de memória, danos cerebrais e outros, com conceitos do modelo Freudiano, isso significaria que seriam uma explicação teórica adequada desde o início por seu fundador, mas esse não é o caso.

\section{Resistência à Testagem}

A maioria dos psicanalistas assume um pressuposto de que a subjetividade humana está acima de todas as possibilidades de análise científica [2021]. Assim, desde a sua fundação e até os dias de hoje com a sua versão contemporânea, a psicanálise carrega uma tradição de ser resistente à testagem de suas hipóteses, sejam sobre eficácia clínica ou construtos teóricos. Melanie Klein, por exemplo, pode ser "desconsiderada do ponto de vista da ciência empírica (...) mesmo que muitas das ideias de Klein fossem baseadas no que ela chamou de 'observação infantil', essas consistiam apenas em especulações sobre o que as crianças poderiam estar pensando" [14, p. 55]. Também, "nunca foram feitas pesquisas empíricas sobre nenhum dos construtos propostos por Lacan" [14, p. 122], 
e "nunca os modelos neofreudianos, nem da psicologia do ego, nem da psicanálise relacional, nem da psicologia do self chegaram a conduzir investigações empíricas, ou investigações dos processos resultantes das abordagens terapêuticas derivadas destas ideias" [14, p. 55-56].

Apesar da divisão de opiniões dentro da comunidade psicanalítica sobre o caráter científico da doutrina, é possível constatar que a maioria dos adeptos tem grande resistência à adoção de ferramentas sistematizadas para obtenção de dados, sob a justificativa de que seu objeto de estudo, o ser humano, seria demasiadamente singular para ser compreendido por uma suposta ciência "positivista", em que só experimentos empíricos seriam permitidos [22]. É explicitamente dito por psicanalistas, por exemplo, que eles acreditam "que hoje é fundamental demonstrar que a psicanálise não necessite de novos fundamentos científicos que seriam fornecidos de forma 'sistemática' e 'segura'" [르, p. 15], que a cura psicanalítica não poderia ser apreendida em termos de critérios de eficácia, como seria feito em psiquiatria [24], e que o estabelecimento de critérios de avaliação da eficácia psicoterápica seriam considerados uma ameaça à subjetividade [20]. Inclusive, há uma oposição clara àqueles que buscam estes objetivos:

"O que podemos constatar na contemporaneidade, é que muitos profissionais do campo psi quando se deparam com o sintoma apresentado pelo sujeito, buscam aniquilá-lo, não se atendo à dimensão ética pela qual o sintoma se manifesta. Isso significa que as vastas propostas psicoterápicas contemporâneas que anunciam ao mundo um modo de tratamento cada vez mais respaldado pela ciência, além da atual proposta no campo da saúde mental que joga insistentemente com a possibilidade de definir uma norma comum, não se comprometem com a experiência que a psicanálise revela (...). Veremos que a psicanálise se coloca como um obstáculo à esta atitude psicológica e médica" [르, p. 242].

Como visto previamente com a definição no sentido ampliado de ciência, a filosofia, a história, a linguística e outras humanidades seriam ciências, mesmo sem utilizar da experimentação tradicional, pois os métodos mais adequados para se alcançar a verdade em tais contextos particulares estariam sendo empregados. Entretanto, a psicologia e a psiquiatria não estão na mesma situação: não há como formarmos as crenças mais epistemicamente justificadas sobre o funcionamento e comportamento humano se não recorrermos às metodologias empíricas e sistemáticas. Seres humanos não têm a capacidade de, apenas com a especulação, formar crenças suficientemente confiáveis sobre tais questões. Então, enquanto a psicanálise rejeita esses métodos, ela não está buscando ser a 
doutrina psicológica que faz as afirmações mais confiáveis de nossa época.

Ao invés disso, alguns de seus adeptos a aproximam cada vez mais de posições relativistas. Isso alimenta a noção de que a ciência consiste apenas em mais um discurso e que ela não poderia clamar ter descrições mais próximas da verdade do que qualquer outro:

"O fato de que a ciência é um discurso se mantém. Tão banal quanto essa afirmação possa parecer, ela implica o destronamento da Ciência e seu reajuste de ciência como um dos discursos dentre muitos outros. Freud pode ser interpretado como tendo traduzido 'racionalidade' para 'racionalização', e o discurso da teoria de Lacan sugere que existem tantas reinvindicações de racionalidade quanto existem diferentes discursos" [26, p. 138].

A ciência é acusada de ser o verdadeiro dogma, e a psicanálise vem para rompê-lo [27]. Sendo assim, ela não precisaria curvar-se aos seus métodos, incluindo à testagem sistemática [22]. Inclusive, aspectos da doutrina psicanalítica têm a finalidade declarada de servirem "de obstáculo epistemológico à tentativa de tratar cientificamente do psiquismo", bem como aos tratamentos baseados em evidências para transtornos mentais [25, p. 237]. A doutrina não admitiria, portanto, ser julgada como qualquer outro campo científico deveria ser, e exige uma proteção especial ao mesmo tempo que busca ter o status que qualquer outro teria, mas isso é descabido. Se o mesmo nível de reconhecimento e valorização é exigido, então ela também deve ser avaliada com exigências similares de rigorosidade e apresentação de provas.

Apesar da grande maioria da comunidade ter essa aversão à testagem das hipóteses, existem algumas exceções à regra. A teoria do apego provavelmente é a revisão da teoria psicanalítica contemporânea mais promissora, por ser a única no âmbito teórico que é mais aberta à testagem de hipóteses e pesquisa empírica [14, p. 62], e por esse mesmo motivo é rejeitada por outros psicanalistas como algo que não faz legitimamente parte da doutrina $[14$, p. 56-57]. Infelizmente, a teoria do apego também não leva em conta aspectos genéticos e temperamentais [14, p. 58], e suas predições entre padrões de apego infantis e a vida adulta são muito fracas [28], enquanto a psicanálise coloca exatamente na vida infantil as principais causas das psicopatologias da maturidade.

Sobre a eficácia psicoterápica, mesmo com grande resistência, alguns estudos foram feitos. Atualmente, psicoterapias de longa duração geralmente não têm evidências convincentes de eficácia, exatamente pela

16 Debates em Psiquiatria, Rio de Janeiro, 2021; 11:1-33 
escassez de estudos empíricos e pela qualidade pobre daqueles já conduzidos, e nessa categoria incluímos a terapia psicanalítica clássica [14]. Um exemplo se dá com a metanálise de Leichsenring e Rabung [29]. Apesar de essa ter sido uma das empreitadas mais citadas para avaliar os efeitos desse tipo de psicoterapia, foi severamente criticada por falhar em todos os critérios de qualidade metodológica exigidos em uma metanálise [30]. Uma das estratégias adotadas por certos psicanalistas para lidar com essa falta de boas evidências costuma ser voltar-se para as suas experiências pessoais, e podemos observar isso em um relatório publicado pela Associação Psicanalítica Internacional:

"É fácil criticar os estudos psicanalíticos. Não há estudos definitivos que mostrem que a psicanálise seja inequivocamente eficaz em relação a um placebo ativo ou a um método alternativo de tratamento. Não existem métodos disponíveis que possam indicar definitivamente a existência de um processo psicanalítico. A maioria dos estudos tem grandes limitações que podem levar os críticos da disciplina a descreditar seus resultados. Outros têm limitações tão graves que mesmo um revisor simpático a ela pode estar inclinado a descreditar as descobertas (...) Como psicanalistas todos sabemos que a psicanálise funciona. Nossa própria experiência de análise é provavelmente suficiente na maioria dos casos para nos convencer de sua efetividade" [31, p. 283].

Para além da psicoterapia psicanalítica clássica, existe uma quantidade maior de estudos sobre a psicoterapia psicodinâmica de curta duração, e estes costumam dar resultados favoráveis a ela [14]. Entretanto, as psicoterapias em geral enfrentam um problema maior do que a discussão corrente neste artigo poderia abarcar. A maioria dos resultados de eficácia psicoterápica, seja qual for a modalidade de psicoterapia, tende a mostrar efeitos positivos, com poucas exceções. Porém, existem evidências de que em muitos casos esses resultados são enviesados, ou tem qualidade metodológica questionável.

Dragioti et al. [32] realizaram uma revisão umbrella de metanálises sobre diversos tipos de psicoterapia (incluindo psicodinâmica) e perceberam que, apesar de quase todos os estudos conduzidos favorecerem as psicoterapias, apenas 16 de 247 metanálises (7\%) foram capazes de fornecer boas evidências sem vieses, e entre essas, nenhuma era de vertentes psicodinâmicas nem psicanalíticas. Para além da discussão sobre a cientificidade da psicanálise, esse certamente é um tópico que necessita de maior atenção por parte dos profissionais da psicologia e da psiquiatria que trabalham na clínica. 


\section{Desdém com Informações Refutantes}

Existem evidências de que muitos dos conceitos-chave da psicanálise são equivocados, mas independente disso, eles continuam sendo adotados no Brasil dentro das universidades e também como embasamento para práticas terapêuticas. A literatura empírica não deu suporte à teoria psicanalítica sobre os sonhos [33], nem às explicações sobre memória e recalque [34]. O cérebro não funciona fazendo registros permanentes dos acontecimentos que são posteriormente recalcados $[14$, p. 30]. Apesar do reconhecimento de que processos inconscientes existem e impactam de modo significativo os seres humanos, o inconsciente psicodinâmico que é governado por desejos recalcados e pulsões não recebe suporte empírico [14, p. 29-30]. Há, como alternativa, a teoria do novo inconsciente, que é mais coerente com as descobertas atuais em neurociências [14, p. 29-30; 18].

A psicanálise costuma ignorar as outras possíveis variáveis (como a genética, classe social e outras) e trata como se um único evento traumático específico no passado infantil do sujeito fosse o causador de transtornos presentes, mas na realidade não temos boas evidências de uma relação de causalidade entre eventos traumáticos específicos de infância e psicopatologias na vida adulta [35]. Outros eventos estressores que ocorrem durante a vida do sujeito têm impactos muito maiores do que os da vida infantil, e desvantagens sociais poderiam explicar mais adequadamente os piores resultados de saúde mental dessas populações [35]. Também não temos evidências de que lembrar de eventos passados seria uma boa rota para a cura de sintomas psicológicos, apesar de esse comumente ser o caminho da análise [14, p. 107]. Mesmo com todas essas disparidades entre os dados científicos e as concepções analíticas, tais conceitos se mantêm vivos até hoje.

\section{Construída em Subterfúgio}

Este item abarca características similares ao criticismo de Popper. Porém, ele não é igual ao critério da falseabilidade, considerando que na falseabilidade o que importa é a possibilidade de uma teoria ser provada 
falsa. Para Popper, não há algo como "confirmação" por indução. Esse item proposto por Hansson capta melhor as doutrinas que possuem designs que supostamente estão sempre confirmando ou que têm como única possibilidade a confirmação da hipótese original, impossibilitando que resultados alternativos sejam possíveis. Sobre isso, Rillaer [36] comenta e fornece diversos exemplos do porquê a psicanálise não poderia ser desconfirmada, apenas constantemente confirmada. Com ela, tudo poderia ser explicado à luz de processos inconscientes, e achar evidências contrárias seria inconcebível:
"Você esquece o seu guarda-chuva na casa de um amigo? Você quer voltar à casa dele (...) Ele reage mal à sua interpretação? 'Ele está se defendendo', está resistindo ao 'id' que fala nele, 'sem que o ego tenha consciência disso'. Ele critica Freud ou Lacan? Está se revoltando contra o Pai (...) Seu filho tem medo de cavalos? Ele teme ser castrado pelo pai porque deseja a mãe. Sua análise faz com que você sofra cada vez mais? Você está entrando enfim nas camadas mais profundas do inconsciente. Os honorários do analista lhe parecem excessivos? Você está tendo uma 'transferência negativa' ou uma 'regressão ao estágio sádico-anal'. Depois de cinco anos de análise, você continua a sofrer de sintomas dolorosos? Você ainda não cavou o suficiente, você deseja sofrer porque seu superego é excessivamente forte" [36, p. 154].

Um psicanalista poderia contra-argumentar que esse seria um caso de psicanálise selvagem, e que dentro da clínica ele não imporia interpretações, mas sim as construiria em uma relação única de troca entre terapeuta e cliente, reservada ao âmbito clínico [37]. Porém, isso não abala a objeção de que a psicanálise é um sistema que opera dentro dessas regras. Não é pela profundidade do diálogo ou o tempo de interação que isso seria diferente.

Boudry e Buekens [38] argumentam que a psicanálise se assemelha a teorias da conspiração, já que os criticismos podem sempre ser taxados como provenientes de uma resistência, que no caso da psicanálise, é inconsciente. Nem quando um crítico ou paciente rejeitam as explicações analíticas isso é visto como desconfirmatório: seria apenas uma confirmação maior de que processos inconscientes inobserváveis estão em curso. Também, se eles concordam com as interpretações oferecidas, a explicação é a mesma: foi um processo originado do inconsciente. Ao final, quando se trata do inconsciente psicodinâmico, não há possibilidade para aceitar evidências contrárias. Para todos os casos, em psicanálise, a "interpretação pode ser uma arma" [39, p. 12].

O excesso de explicações que se encaixariam para todo e qualquer caso, portanto, não se mostra explicativo de fato; apenas aparenta ser. As 
interpretações escolhidas para abordar os fenômenos do funcionamento psicológico humano não são baseadas em boas evidências científicas cuidadosamente colhidas. Ao invés disso, costumam ser conceitos desprovidos de respaldo empírico, usados para explicar qualquer comportamento e também o seu oposto. "A psicanálise é propriamente irrefutável, pois ela pode dizer tudo e seu contrário - basta invocar o 'servil' testemunho do inconsciente, sempre pronto para se curvar às exigências do momento" [느, p. 140].

\section{Explicações são Abandonadas sem Substituição}

As definições dadas aos conceitos de cura, saúde e doença em psicanálise se enquadram neste critério. Para Neves [23] a discussão sobre a cura na psicanálise contemporânea não pode ocorrer caso não comece por uma crítica à noção tradicional do termo, e o mesmo vale para os outros dois conceitos. O autor argumenta que a psicanálise entende que, para a medicina, que adota o uso tradicional desses, um estado de saúde deveria ser um estado harmonioso completamente livre de doenças e patologias. Inclusive, diferentemente dos objetivos médicos, Priszkulnik [41] afirma que "a psicanálise se opõe ao objetivo da saúde mental de reintegrar o indivíduo à comunidade social". Ainda de acordo com Neves [23] , os psicanalistas entendem que, para a medicina, a "cura" significaria uma conformação a um modo de funcionamento idealizado e baseado em noções de normalidade socialmente aceitas e esperadas, partindo da eliminação das doenças e o reestabelecimento da saúde anteriormente presente. Ou também, mais sucintamente, ela seria "a realização de uma experiência que conduz o sujeito à saúde pela eliminação da doença" [므, p. 33].

Considerando a definição tradicional, a psicanálise acusaria a existência de intenções ocultas por trás do objetivo de curar pessoas em sofrimento: isso seria, na realidade, uma tentativa de controle social [23, p. 16]. Assim, faria mais sentido estar desamparado do que curado, pois:

"Não devemos esquecer que estar desamparado, do ponto de vista psicanalítico e político, significa em larga medida ter atravessado o fantasma do amparo infinito pelo poder instituído. Estar desamparado (...) é sustentar a ação política como ação que força o impossível não cessar de não se escrever na situação" 
$[\underline{23}$, p. 28].

Para alguns, como Nasio, não faria sentido nem mesmo conceber cura como um conceito:

"Não podemos dizer que a cura, assim compreendida como diminuição ou desaparecimento do sofrimento ligado aos sintomas, seja um conceito psicanalítico. Também não podemos dizer que ela seja um objetivo para o qual o tratamento deva tender, nem um critério que nos permita avaliar os seus progressos (...) não podemos fazer da cura nem um conceito, nem um objetivo, nem um critério, o que equivale a não ceder diante da influência do modelo médico, que tende a hipostasiar essa cura, a lhe dar um estatuto, a elevá-la à dignidade de um conceito (...) não existe conceito psicanalítico de cura, e que esta não pode ser uma finalidade que o analista deva perseguir na sua prática, como acontece na medicina" [42, p. 160].

Mesmo com essas considerações, existem propostas de novas definições que supostamente substituíram as tradicionais: no entanto, elas geralmente são vazias e piores do que as anteriores. "A saúde em psicanálise só pode ser compreendida como uma normatividade que se individualiza, sendo então impossível pensá-la como a expressão de um valor absoluto, ou seja, de uma norma geral" [23, p. 28]. Também poderia ser acrescida a observação de que "é certo que a psicanálise não toma a saúde como elemento constitutivo de sua ética e política de cura" [43, p. 23]. Sobre a definição de doença, poderíamos entendê-la em psicanálise como sendo "uma experiência produtiva de indeterminação" [23, p. 18], não deixando de considerar que também "a doença, seja ela psíquica ou orgânica, não significa outra coisa senão a redução da margem de tolerância às modificações do meio" [23, p. 28]. Inclusive, existiria algo de especial dentro do campo da doença: "estar doente é, a princípio, assumir uma identidade com grande força performativa" [44, p. 293], e o ideal curativo "visa enfraquecer o poder que habita as experiências do patológico, do anormal, do inumano e do desamparo" [23, p. 21].

Já para a cura, diversas opções são oferecidas em psicanálise. Algumas podem ser consideradas: "curar-se é, portanto, construir e experimentar uma nova ordem, ou seja, a cura envolve viver inéditas formas de ajustamento ao meio" [ 23 , p. 18]. Ou também, "realizar uma experiência que não tem lugar e não pode se inscrever na situação" [233, p. 8]. Para os psicanalistas, "a cura na experiência psicanalítica pode ser definida, fundamentalmente, pela ideia de transformação, isto é, da realização de uma experiência subjetiva que não é o restabelecimento da norma ou do resultado previsto da execução de um método de tratamento" [23, p. 84]. Dunker e Peron [24, p. 89] argumentam que o conceito de cura pode ter 
diversas interpretações a partir da obra de Freud, além delas não se relacionarem às tradicionais da medicina. Uma delas poderia ser a de que a "cura coincide com o conhecimento das causas dos sintomas" [ 24 , p. 86]. Já na visão de Neves [23 , p. 25], os trabalhos de Freud e de Lacan teriam deixado de legado a definição de cura como sendo a realização de uma experiência que toca o impossível. Para Nasio "a cura é um valor imaginário, uma opinião, um preconceito, um pré-conceito, assim como o são a natureza, a felicidade ou a justiça" [42, p. 160]. Não apenas isso, mas pelas definições dadas em psicanálise "a cura como a realização de uma experiência singular não será idêntica a nada" [43, p. 24]. De todo modo, é importante estar atento para o fato de que mesmo se ela for entendida dessas maneiras adaptadas pela doutrina e inclusive pelo próprio Freud como uma "reorganização do Eu", ela continua sendo um ideal "nocivo à análise e ao psicanalista" [42, p. 167]: um terapeuta que busca a cura de seu paciente estaria possivelmente sob influência de sentimentos de orgulho e narcisismo [42, p. 168]. A psicanálise, mesmo sendo tratada como uma psicoterapia, não tem a cura como meta nas palavras de Lacan, citado por Nasio:
"(...) o mecanismo (da análise) não é orientado para a cura como finalidade. Não digo nada que Freud já não tenha formulado poderosamente: toda inflexão em direção à cura como finalidade - fazendo da análise um meio puro e simples para um fim preciso - dá algo que estaria ligado ao meio mais curto que só poderia falsear a análise" [42, p. 159].

Para a psicanálise, a definição de cura como uma experiência que conduz à saúde deve ser substituída por uma experiência que não está em lugar nenhum, não diz respeito a nenhuma situação possível, que não tem nada a ver com os objetivos propostos por um tratamento, e que é impossível. Ela não seria idêntica a nada, e se não é idêntica a nada, não poderia nem ser idêntica a si mesma, o que configuraria uma contradição lógica. Em psicanálise, a cura é imaginária, e inclusive nociva. No caso da saúde, essa seria uma normatividade individualizada que não está incluída nas demandas éticas da doutrina. Enquanto isso, as tentativas de tratar adoecimentos são acusadas de consistirem em tentativas de controle social, e influenciadas por narcisismo e orgulho. As doenças e as patologias não poderiam, em psicanálise, ser consideradas como um desvio da norma orgânica, mas em vez disso, são classificadas como fontes de algum tipo de poder renegado, em vez de sofrimento. Esses conceitos, em suas muitas variações, são apresentados como supostas substituições para as ideias 
tradicionais de cura, saúde e doença. Porém, mesmo que as definições tradicionais possam ser criticadas e possuam lacunas, as definições adotadas em psicanálise tornam esses conceitos muito mais vagos e distantes da realidade do que suas versões originais, com alguns deles ao ponto de nem mesmo serem compreensíveis. Isso torna a nova proposta muito menos explicativa do que a tradicional.

Nessa situação existem pelo menos dois problemas: para além de haverem explicações (no caso, definições) abandonadas sem uma boa substituição, esse também é um caso de obscurantismo. Considerando esse aspecto da doutrina, que não se restringe às definições dos três conceitos apresentadas nessa seção, isto pode sugerir que o sétimo critério da lista de Hansson talvez seja insuficiente para captar outros problemas relativos ao modo como as explicações de uma doutrina pseudocientífica são tratadas. Levando isso em conta, neste artigo haverá a proposta de um novo item, introduzido com um oitavo a ser adicionado à lista original. Poderia ser assim colocado:

8. Obscurantismo: Os conceitos teóricos ou afirmações de uma teoria possuem um significado inexistente ou nebuloso ao entendimento, o que permite a realização de mudanças arbitrárias, ou seja, sem que existam justificativas plausíveis para tal.

\section{Obscurantismo}

Muito se poderia dizer sobre o problema do obscurantismo, sua relação com a pseudociência e também sua pertinência como critério de demarcação. Entretanto, não há aqui uma revogação de exaustão, apesar de serem oferecidas as seguintes explicações para a introdução desse novo item:

O obscurantismo é um estilo comunicativo, comumente utilizado por pseudocientistas como estratégia retórica, que ocorre nos casos em que a apresentação das afirmações ou dos conceitos de uma teoria são feitos de maneira significativamente imprecisa, impedindo uma compreensão adequada de sua proposta. Isso a protege de possíveis objeções: já que suas definições são demasiadamente vagas, é sempre possível acusar o crítico de não ter compreendido seu real sentido, bem como alternar as definições de modo a adotar ou abandonar os seus variados significados, usando-os respectivamente nos momentos mais oportunos. 
Um texto obscurantista, apesar de aparentar trazer um conteúdo robusto sobre um determinado tópico, na realidade não o faz [10]. Isso parece relevante principalmente quando retornamos à definição de pseudociência: de maneira semelhante, no caso do obscurantismo, é criada uma impressão de cientificidade enquanto há um afastamento considerável da ciência (no sentido ampliado). Por essa razão, a introdução desse item parece ser justificada.

Em certos casos de obscurantismo, diversas afirmações são feitas, mas na realidade estas são proclamadas através de frases destituídas de valor de verdade, ou seja, frases que não podem ser verdadeiras nem falsas. Em outros, mesmo que algum significado possa ser de lá retirado, uma nebulosidade sobre sua real definição é imposta pelo autor, impedindo que os leitores tracem interpretações mais precisas ou consensuais sobre o que realmente se quis dizer. Isso dificulta a própria produção de objeções: é muito mais trabalhoso criticar uma posição que não se consegue compreender adequadamente do que aquela que expõe seus raciocínios de maneira clara e explícita. Também é importante notar que em diversos momentos as reformulações de conceitos são importantes para a ciência, mas para fazê-las, é necessário que existam boas justificativas. Isso não costuma ser levado em consideração pelo obscurantista.

No caso da psicanálise, certas coisas mudaram dos tempos de Freud para os dias atuais, mas além de não terem sido muitas, também não foram adotadas frente ao surgimento de boas evidências. As grandes teorias da psicanálise contemporânea continuam sem passar por testes empíricos [14], evidenciando que as mudanças foram arbitrárias, e provavelmente visavam apenas adaptar-se ao meio cultural da época. Um exemplo desse tipo de ocorrido é a alteração do status patológico da orientação sexual de gays e lésbicas, bem como a questão da inveja do pênis [4]]. Uma teoria supostamente evoluir e mudar os seus conceitos ao longo do tempo só é um mérito se a mudança for feita com base em boas evidências, e não apenas por influências culturais; afinal, até mesmo os movimentos religiosos mudam suas explicações sobre o mundo ao longo dos séculos, e isso não contribui para torná-los científicos.

Cioffi [4] aponta que o papel etiológico da sexualidade sofreu com uma mudança de significados oportunista. As ideias de sexualidade, de erotismo e de libido tinham suas definições escolhidas arbitrariamente por Freud dependendo do contexto: quando eram questionadas pelo cético, se 
tornavam algo que simbolizaria o amor fraterno, afeto, ou no caso das pulsões sexuais seriam desejos que poderiam ser satisfeitos utilizando-se dos mais variados sentidos, inclusive de modo não genital. Enquanto isso, em ambientes mais seguros e receptivos, essas convenientemente voltavam a significar questões sexuais no sentido tradicional dos termos.

"Sendo a teoria psicanalítica perfeitamente vazia, ela é também, ao mesmo tempo, supremamente adaptável. Tal ou qual outro conceito da teoria se mostra dificilmente sustentável, ou mesmo francamente embaraçador, (...) basta abandoná-lo silenciosamente e tirar um novo coelho teórico da imensa cartola do inconsciente. Isso é o que os psicanalistas gostam de descrever como os 'progressos' da psicanálise (...). O que é dado como um progresso em psicanálise não é senão a última interpretação, ou seja, a mais aceitável em um determinado contexto institucional, histórico ou cultural" [40, p. 140-141].

Buekens e Boudry [10] mostram que a psicanálise lacaniana é outro exemplo de obscurantismo. Lacan assume que 0 inconsciente é estruturado como uma linguagem e defende que sua escrita seria equivalente à expressão de seu próprio inconsciente. A adoção da linguagem obscurantista, então, é assim justificada. Desse modo, qualquer tentativa mais sistemática de interpretá-lo estaria fadada a ser vítima de erro, imunizando a doutrina de possíveis criticismos. Mesmo que Lacan se portasse como uma autoridade sobre a psicologia humana que transmitia suas ideias através de significados ocultos, caberia ao leitor interpretá-las (em suas inúmeras possibilidades de fazê-lo), ainda podendo sempre ser acusado de não o ter compreendido de fato.

Buekens e Boudry [10] apontam também que, como não é possível traçar conclusões definitivas sobre o que Lacan realmente quis dizer, só resta ao leitor entendê-lo subjetivamente de acordo com suas impressões pessoais, o que acaba criando uma divergência significativa de interpretações entre os próprios adeptos. O psicanalista não apenas se utilizava de uma linguagem obscurantista em seus trabalhos, mas também assumiu explicitamente seu uso:

"Eu diria que é com uma intenção deliberada, se não totalmente deliberada, que eu faço esse discurso de modo a oferecer para vocês a oportunidade de não entenderem. Essa margem permite a vocês dizerem que pensam que me seguem, quer dizer, vocês se mantêm em uma posição problemática, em que a porta está sempre aberta para uma progressiva retificação" [45, p. 164]. 


\section{Conclusão}

Este artigo apontou que a psicanálise - não apenas em sua versão clássica, mas também a contemporânea - se enquadra em todos os sete itens da lista de multicritérios de Hansson. Ela também se encaixa no oitavo item apresentado neste trabalho. Assim, ao final, ela acaba por ser compatível com todos os oito itens de demarcação de pseudociências. As evidências apresentadas sugerem que, tanto com o critério de Popper quanto com o de Hansson, e também considerando suas versões clássicas e contemporâneas, a psicanálise é de fato uma pseudociência. Mesmo se a impressão de que fornece as afirmações mais confiáveis sobre o funcionamento psicológico humano seja criado por seus proponentes, esse não é o caso, porque ela se desvia consideravelmente dos critérios de qualidade científicos.

Apesar da pesquisa em psicanálise ser extremamente difundida no Brasil, as suas objeções não estão sendo discutidas na literatura, e isso pode ser um indicador de alienação [46]. A manutenção de uma postura dogmática sobre uma doutrina inserida no meio acadêmico é perigosa, já que pode levar à estagnação da ciência e impedir o pleno desenvolvimento de suas disciplinas, que no caso da psicanálise, seriam principalmente a psicologia e a psiquiatria. É importante que as críticas à psicanálise sejam mais discutidas, dado que ela ainda é tratada na academia como um dos principais modelos teóricos e clínicos para o entendimento do comportamento humano. Mesmo a partir de uma perspectiva ética, é importante buscarmos realizar práticas e construir teorias que estejam de acordo com as melhores evidências científicas. Não há uma boa justificativa moral para acreditarmos em seja qual teoria for se ela não possuir evidências suficientes a seu favor [4]].

\section{Agradecimentos}

Agradeço a Alícia Cristina de Sales Braga, Vitor Douglas de Andrade e Caio César de Souza Barbosa pelos diferentes tipos de incentivo e apoio recebidos em fases diversas do desenvolvimento deste artigo. 


\section{Referências}

1 Laplanche J, Pontalis J-B. Vocabulário da Psicanálise. 9a ed. São Paulo: Livraria Martins Fontes, 1986.

2 Popper KR. Conjecturas e Refutações: O Progresso do Conhecimento Científico. 5a ed. Brasília: UNB, 2008.

3 Grünbaum A. Popper's fundamental misdiagnosis of the scientific defects of Freudian psychoanalysis and of their bearing on the theory of demarcation. Psychoanal Psychol. 2008;25:574-89.

https://doi.org/10.1037/a0013540

4 Cioffi F. Pseudoscience: the case of Freud's sexual etiology of the neuroses. In: Pigliucci M, Boudry M, editors. Philosophy of pseudoscience: reconsidering the demarcation problem. Chicago \& London: University of Chicago Press; 2013. p. 321-40. https://doi.org/10.7208/chicago/9780226051826.003.0018

5 Newton-Smith WH. The Rationality of Science. London e New York: Routledge, 2003. https://doi.org/10.4324/9780203046159

6 Hansson SO. Disciplines, Doctrines, and Deviant Science. International Studies in the Philosophy of Science. 2020;33:43-52. https://doi.org/10.1080/02698595.2020.1831258

贾7 Hansson SO. Defining Pseudoscience and Science. In: Pigliucci M \& Boudry M, editores. Philosophy of Pseudoscience: Reconsidering the Demarcation Problem. Chicago e London: The University of Chicago Press; 2013. p. 61-78.

https://doi.org/10.7208/chicago/9780226051826.003.0005

8 Hansson SO. Vetenskap och ovetenskap. Stockholm: Tiden, 1983.

9 Crews F. Freud: The Making of an Illusion. New York: Metropolitan Books, 2017. 
10 Buekens F, Boudry M. The Dark Side of the Loon. Explaining the Temptations of Obscurantism. Theoria. 2014;81:126-42.

https://doi.org/10.1111/theo.12047

11 Dersken AA. The Seven Strategies of the Sophisticated PseudoScientist: A Look into Freud's Rhetorical Tool Box. J Gen Philos Sci. 1993;32:329-50. https://doi.org/10.1023/A:1013100717113

12 Borch-Jacobsen M. Les patients de Freud: Destins. Auxerre: Science Humaines, 2011. https://doi.org/10.3917/sh.jacob.2011.01

13 Figueiredo LC. A Psicanálise e a clínica contemporânea.

Contemporânea: Psicanálise e Transdisciplinaridade. 2009;15:9-17. http://www.revistacontemporanea.org.br/revistacontemporaneaanterio r/site/wp-content/artigos/artigo202.pdf

14 Paris J. An Evidence-Based Critique of Contemporary

Psychoanalysis: Research, Theory, and Clinical Practice. London e New York: Routledge, 2019. https://doi.org/10.4324/9780429020674

15 Schmidt S. Shall we Really do it Again? The Powerful Concept of Replication is Neglected in the Social Sciences. Rev Gen Psychol. 2009;13:90-100. https://doi.org/10.1037/a0015108

16 Kahneman D. Thinking, Fast and Slow. New York: Farrar, Straus and Giroux, 2011. 
17 Spence DP. Dangers of Anecdotal Reports. J Clin Psychol. 2001;57:37-41. https://doi.org/10.1002/10974679(200101)57:1<37::AID-JCLP5>3.0.CO;2-S

18 Callegaro MM. O Novo Inconsciente: Como a Terapia Cognitiva e as Neurociências Revolucionaram o Modelo do Processamento Mental. Porto Alegre: Artmed, 2011.

- 19 Ramus F. What's the point of neuropsychoanalysis?. Br J Psychiatry. 2013;203:170-1. https://doi.org/10.1192/bjp.bp.113.127217

PMid:23999480

20 Bastos LADM. Psicanálise baseada em evidências?. Physis. 2002;12:391-408. https://doi.org/10.1590/S0103$\underline{73312002000200011}$

21 Guerra AMC. Psicanálise e Produção Científica. In: Neto FK \& Moreira JO, organizadores. Pesquisa em Psicanálise: Transmissão na Universidade. Barbacena: EdUEMG; 2010. p. 130-145.

22 Lage SFL. Dilthey e Freud: A psicanálise frente à epistemologia das ciências do espírito [dissertação]. Rio de Janeiro: Repositório Maxwell; 2003. https://doi.org/10.17771/PUCRio.acad.4047

23 Neves TI. A Cura em Psicanálise como Potência Política de Transformação [tese]. Recife: Universidade Católica de Pernambuco; 2018. http://tede2.unicap.br:8080/handle/tede/995

24 Dunker CIL, Peron PR. Usos e sentidos da cura na psicanálise de Freud. Percurso. 2002;83-9.

25 Neves TI, Lopes AM, Moraes TCB. Reintroduzindo o sintoma: a 
psicanálise como obstáculo à cientificização do tratamento psíquico. Estud. Pesqui. Psicol. 2013;13:237-53.

https://doi.org/10.12957/epp.2013.7934

26 Fink B. The Lacanian Subject: Between Language and Jouissance. Princeton, New Jersey: Princeton University Press, 1995. https://doi.org/10.1515/9781400885671

- 27 Sgarioni MM, D'Agord MRL. Ciência, verdade e saber na sociedade moderna: uma perspectiva psicanalítica. Clín Cult. 2013;2:3-15. https://seer.ufs.br/index.php/clinicaecultura/article/view/926

28 Fearon RMP, Roisman GI. Attachment theory: Progress and future directions. Curr Opin Psychol. 2017;15:131-6. https://doi.org/10.1016/j.copsyc.2017.03.002 PMid:28813253

29 Leichsenring F, Rabung S. Effectiveness of long-term psychodynamic psychotherapy: A meta-analysis. JAMA. 2008;300:1551-65. https://doi.org/10.1001/jama.300.13.1551

PMid: 18827212

30 Littell JH, Shlonsky A. Making Sense of Meta-Analysis: A Critique of "Effectiveness of Long-Term Psychodynamic Psychotherapy". Clin Soc Work J. 2010;39:340-6. https://doi.org/10.1007/s10615-010-0308-z

31 Fonagy P. An open door review of outcome studies in psychoanalysis. International Psychoanalytical Association, 2002. [citado 26 Jan 2021]. https://www.ipa.world/ipa/IPA Docs/Open\%20Door\%202002.pdf

32 Dragioti E, Karathanos V, Gerdle B, Evangelou E. Does psychotherapy work? An umbrella review of meta-analyses of randomized controlled trials. Acta Psychiatr Scand. 2017;136:236-46. https://doi.org/10.1111/acps.12713 PMid:28240781 
33 Hobson A. Psychodynamic Neurology: Dreams, Consciousness, and Virtual Reality. Boston, Massachusetts, USA: CRC Press, 2015. https://doi.org/10.1201/b17676

- 34 Rofé Y. Does repression exist? Memory, pathogenic, unconscious and clinical evidence. Rev Gen Psychol. 2008;12:63-85.

https://doi.org/10.1037/1089-2680.12.1.63

35 Horwitz AV, Widom CS, Mclaughlin J, White HR. The Impact of Childhood Abuse and Neglect on Adult Mental Health: A Prospective Study. J Health Soc Behav. 2001;42:184-201. https://doi.org/10.2307/3090177

36 Rillaer JV. Os Benefícios da Psicanálise. In: Meyer C, organizadora. O Livro Negro da Psicanálise. $3^{a}$ ed. Rio de Janeiro: Civilização Brasileira; 2014. p. 147-162.

37 Grant DC, Harari E. Psychoanalysis, Science and the Seductive Theory of Karl Popper. Aust N Z J Psychiatry. 2005;39:446-52. https://doi.org/10.1080/j.1440-1614.2005.01602.x PMid:15943645

38 Boudry M, Buekens F. The Epistemic Predicament of a Pseudoscience: Social Constructivism Confronts Freudian Psychoanalysis. Theoria. 2011;77:159-79. https://doi.org/10.1111/j.1755-2567.2011.01098.x

39 Frosh S. For and Against Psychoanalysis. London e New York: Routledge, 2006.

40 Borch-Jacobsen M. Uma Teoria Zero. In: Meyer C, organizadora. O Livro Negro da Psicanálise. $3^{a}$ ed. Rio de Janeiro: Civilização Brasileira; 2014. p. 137-142.

41 Priszkulnik L. Prevenção: saúde mental e psicanálise. Proceedings of 
the 7th Formação de Profissionais e a Criança-Sujeito. LEPSI IP/FEUSP, 2009.

http://www.proceedings.scielo.br/scielo.php?pid=MSC0000000032008 $\underline{000100002 \& \text { script }=\text { sci } \text { arttext }}$

42 Nasio J-D. Como trabalha um psicanalista? Rio de Janeiro: Zahar, 1999.

43 Neves TI. O universalismo da cura em Freud. Ágora (Rio J. Online). 2020;23:21-9. https://doi.org/10.1590/1809-44142020001003

44 Safatle V. O circuito dos afetos. São Paulo: Cosac Naify, 2015.

45 Lacan J. The Seminar of Jacques Lacan: Book III, The Psychoses. Miller J, editor. New York and London: W. W. Norton, 1997.

46 Fontes FF. A crítica à psicanálise: Um capítulo censurado? Psicol rev. 2014;20:446-59. https://doi.org/10.5752/P.1678-9523.2014V20N3P446

-47 Clifford WK. A Ética da Crença. In: Murcho D, organizador. A Ética da Crença. Lisboa: Bizâncio, 2010. p. 97-136. 


\section{Clarice de Medeiros Chaves Ferreira}

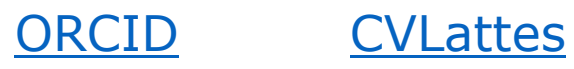

